\title{
CANTANDO A TORÁ
}

\section{CHANTING THE TORAH}

\author{
Pedro Juliano Dellarole \\ Universidade de São Paulo \\ pedrodellarole@usp.br
}

\section{Resumo}

Este trabalho pretende esboçar uma breve introdução à cantilação judaica em português. A antiga e rica tradição milenar de cantar e reinterpretar a tora ou biblia hebraica conhecida por te amim ha-mikra (cantilenas). Este fenômeno litúrgico musical permitiu a um determinado grupo de pessoas a estruturar um sistema organizacional com a qual implementaram um agrupamento de som funcional de leitura bíblica que mais tarde veio a ser escrito por meio de notações musicais, propagando-se através das diferentes vertentes judaicas.

Ao longo de séculos, distintas comunidades judaicas se desenvolveram de forma única e passaram por diversas assimilações culturais. Por meio destas notações musicais, conseguiram preservar sua tradição oral de cantar a torá. Por onde se estabeleciam criavam percepções diferenciadas nas cantilenas, acabam influenciando e sendo influenciados pelos sons da cultura local dominante.

Palavras-chave: Musicologia; Etnomusicologia; Teoria Musical; Historiografia; Hermenêutica; Performance; Canto; Judaísmo.

\section{Abstract}

This work aims to outline a brief introduction to Jewish singing in Portuguese. An ancient and rich tradition of singing and reinterpreting a - torah or bible known as Te amim ha-mikra. This liturgical musical phenomenon allowed a group of people determined to structure an organizational system with a functional reading or recording system that later came to be written by means of musical notations, spreading through different Jewish strands. 
Over the centuries, different Jewish communities developed in a unique way and went through several cultural assimilations. Through these musical notations, they were able to preserve his oral tradition of singing the Torah. Where they settled created different perceptions in the cantillations, because they end up influencing and being influenced by the sounds of the dominat local culture.

Keywords: Musicology; Ethnomusicology; Musical theory; Historiography; Hermeneutics; Performance; Chant; Judaism.

\section{Primícias musicais}

Os seres humanos diferenciam-se dos outros seres, entre outras coisas, pela constante atualização e enorme complexidade da memória. Na rica fenomenologia da lembrança, o registro do passado é parte da necessidade humana de refletir, é a aspiração de explicar a origem das experiências vividas, para uma compreensão do presente e uma antecipação do futuro.

Para responder sobre sua existência contemporânea e conhecer a si mesmo, os seres humanos têm de imergir no seu passado. Através da História, buscamos nossa identidade para compreender o momento presente, podendo essa compreensão ocorrer sobre pontos de vista culturais, sociológicos e antropológicos. Para Marc Bloch, o homem é o sujeito de sua história e de que a história não pode ser apenas atrelada a fatos, ou relatos (BLOCH, 2002).

Desde da Antiguidade são atribuidos à música todas as categorias de emoções e poderes até mesmo sobrenaturais sobre o individuo que a executa.A primeira grande força social a ter considerado o poder da música no ocidente foi a religião. Esta estabelece e sistematiza o ritual. Segundo Cristopher Small ritual seria: "um ato que dramatiza e encena a mitologia compartilhada de uma cultura ou de um grupo social, é a mitologia que unifica $e$, para os membros, justifica tal cultura ou grupo" (SMALL in WHITE, 1987).

A música e os músicos são objeto de uma aliança histórica com a religião, colocada sob o signo da dominação e subordinação (ADENOT, 2008). A música na vida e no pensamento da Grécia Antiga sempre esteve por muito tempo associada à origem divina e designava como 
seus inventores e intérpretes deuses e semideuses, como Apolo, Anfião e Orfeu (CROUT; PALISCA, 2007). Sempre foram atribuídos à música (poderes) mágicos tais como curar doenças, purificar o corpo e outros milagres relativos a natureza. No Tanach' (TANACH..., 2008) se atribui à música os mesmos poderes. $\bigcirc$ episódio em que o rei David cura a loucura de Saul tocando harpa ( I Samuel, 16, 14:23) ou o soar das trombetas ou shofarot ${ }^{2}$ em hebraico, foram utilizados na queda das muralhas de Jericó. (Josué, 6, 12:20). Bruno Nettl observa que: "o ser humano urge para se comunicar com o ser sobrenatural através da música. Uma vez que foram os deuses que trouxeram a música para a humanidade, seria natural que ela seja de fato, o veículo de comunicação entre o mundano e as esferas celestiai" (NETTL, 1983, p. 165).

No livro de Jó o profeta podemos ouvir a voz de Deus descrevendo a majestade do Cosmos no início de sua criação: "Quando as estrelas da alva juntas alegremente cantavam, e todos os filhos de Deus jubilavam" (TANACH, 2008, 38:7).

Em shacharit, oração matinal judaica, encontramos um trecho que antecede o keriat shemá, que faz uma alusão descritiva do imaginário coletivo humano, propondo louvores angelicais que foi posteriormente incorporado dentro da liturgia diária judaica (FRIDLIN, 1997, p. 59), "E os anjos Ofanim, e as criaturas, anjos Chaiot, com grande ruido levantamse dirigindo-se frente aos sefarim, louvam e dizem: "Bendito é a Clória do Eterno na Mansão". Ao Rei vivo e firme, salmodiam hinos e anunciam louvores; porque só Ele é alto e Santo".

A música encontrada no texto bíblico leva-nos até ao tempo do nomadismo do povo judaico, bem como à época dos profetas, depois do exilio. É difícil, no entanto, conseguir uma imagem histórica compreensivel, com base nos documentos existentes.

Para Alfred Goodman mais importante do ponto de vista histórico é o canto antifonal que sobrevive até aos nossos dias em diversas

I Tanach é um acrônimo utilizado no judaísmo para denominar o seu principal conjunto sagrado de livros, sendo o mais próximo que se possa chamar de Bíblia Hebraica.O Tanach é composto por vinte e quatro livros. A palavra é formada pelas iniciais das palvras que as compôe: Torah, Neviim e Ketuvim.

2 Shofar ou Shofarot no plural é um antigo instrumento de sopro citado em diversas passagens bíblicas tocado nas sinagogas até nos dias atuais.É feito de chifre de carneiro ou de um outro animal casher (animal permitido pelas leis alimentares do judaísmo), assim como o antílope. 
comunidades judaicas orientais, com especial relevância para os lemenitas, cujas mulheres têm um papel dominante.

As formas primitivas antífonas cantadas por homens maioritariamente alicerçado em cânticos litúrgicos consiste a maior parte das vezes, em secções intercaladas de canto e resposta (refrão), interpretadas pelo solista e pelo coro. Este estilo de música ainda é executado hoje em dia ainda que em estilo reformado, tomando a forma de prece lírica e salmos recitados que se foram desenvolvendo ao longo dos séculos. Desta maneira "teatros de música religiosa", com grupos instrumentais e comunidades corais (coros) foram-se lentamente cristalizando e desenvolvendo, conduzindo às escolas integradas em templos, onde os futuros músicos aprendem a cantar e tocar os respectivos instrumentos (COODMAN, 1982).

Ė importante fazer uma distinção entre funções religiosas do templo e da sinagoga. O templo ou seja, o segundo templo de Jerusalém, que existiu no memso lugar do primerio templo do rei Salomão de 539 a. C. até sua destruição pelos Romanos em 70 d. C. era um local de culto e devoção. Sacrifícios de farinha azeite e animais eram conduzidos por sacerdotes (cohanim), assistidos por Levitas, entre os quais haviam músicos e leigos israelitas. Os sacerdotes e os Levitas comiam parte destes sacrifícios que eram realizados diariamente, de manhã e de tarde; no shabat (sábado) e em outras festividades de peregrinção. De acordo com Goodman, na época de Salomão, houve um desenvolvimento da cultura musical e do ensino da música entre os judeus. $\bigcirc$ ensino e aprendizagem foi encorajado. Depois da divisão do império salomódico, as tradições religiosas foram notavelmente negligenciadas.

Conforme Goodman: "A permanência da música litúrgica em forma de "pneuma" executada pelo coro em uníssono, foi sendo transformada em apenas solos. Quando era prevista uma canção para acompanhar a adoração de uma forma mais sugestiva, foi a mesma transformada numa canção falada ou em apenas uma declamação".

[...] Enquanto decorria o sacrifício, um coro de levitas com doze elementos, pelo menos cantava um salmo, diferente para cada dia da semana, acompanhado por instrumentos de cordas. Nas festas mais importantes como a véspera da Páscoa, cantavam-se os salmos 113 a 118 , que tem refrões

\section{5}

REV. TULHA, RIBEIRÃO PRETO, v. 6, n. I, pp. 52-77, jan.-jun. 2020 
de alelvia, os crentes faziam os sacrifícios pessoais, e em seguida, um instrumento de sopro semelhante ao aulo vinha associar-se ao acompanhamento de cordas [...] (CROUT; PALISCA, 2007, p. 35).

Uma que vez que o templo deixou de existir, todos os seus rituais e simbolismosforam transferidos para as sinagogas ou para as casas das pessoas que a frequentavam. Com o passar do tempo, esses lugares tornaram-se em centros comunitários, de estudos da Torá e homilia.

Devido à dispersão dos judeus depois da destruição do tempo em 70 d.C. para muitas áreas do Império Romano, com diferentes culturas musicais, as melodias utilizadas no templo sofreram diversas modificações e adaptações. Unterman comenta que:

\begin{abstract}
[...] Desestimulou-se o uso de instrumentos musicais apos a destruição do templo, como expressão de luto, e o órgão é o único instrumento usado hoje nas sinagogas ortodoxas, e somente em casamentos. As congregações reformistas introduziram alguns instrumentos como parte litúrgica do shabat (sábado) e nas festas. A maior parte da música é vocal, seja a música cantoria dos Chazanim (cantores) e do coro da sinagoga, sejam as melodias usadas para entoar os textos das preces, da Torah e de outros livros bíblicos, sejam as canções cantadas em casa (Zemirot) e nas reuniões comunitarias [...] (UNTERMAN, 1992).
\end{abstract}

A arte da salmodia dentre diversas versões dos cânticos do antifonal, entrecortados por respostas relacionadas ao refrão da comunidade, caiu em desuso a partir do último século antes da Era Comum. Coodman afirma que estudos posteriores permitem-nos saber que os cânticos do antifonal não eram incluídos nos serviços litúrgicos. Nas sinagogas na diáspora, foram-se acentuando as características das velhas liturgias com a declamação de salmodistas com emprego de solistas, entrecortadas com aclamações ou refrões da congregação, o que também pode ser observado nas igrejas cristãs deste período.

Aharon Ben Moses Ben Asher (895 d. C.), desempenhou um papel determinante por conta de sua pesquisa acerca do "Canto falado" ou cantilena. $O$ salmodismo hebreu desenvolveu-se no sentido

\title{
56
}

REV. TULHA, RIBEIRÃO PRETO, v. 6, n. I, pp. 52-77, jan.-jun. 2020 
de uma melodia sintática que passou a ser utilizada nas cerimônias religiosas. Neste caso, esta declamação do oficiante, contribuiu para a institucionalização dos téamim ha-mikra. Maimônedes, filósofo e comentarista bíblico, contribuiu muito para estabelecer e difundir sua autoridade. Referindo-se a um manuscrito bíblico no Egito ele escreveu: "Tenho plena confiança, uma vez que foi corrigido por Ben Asher e foi trabalhado e analisado por ele por muitos anos, e foi revisado muitas vezes de acordo com a masorah, basei-me neste manuscrito para escrever o Sefer Torá" (livro da torá).

Demorou, no entanto, mais do que um milênio para que se estabelecesse uma sistematização, além do registo escrito dos acidentes, das caracterizações na renovação, do desenvolvimento do material musical e sua simbologia. A estrutura básica da música que se desenvolveu ao longo dos anos e que chegou até os nossos dias, vem da tradição dos Salmos de David (mizmor le David). Esses foram-se renovando ao longo dos séculos e declamados em forma de cânticos modelados no estilo salmódico. Salmodia, leitura e hinologia formam as bases do canto litúrgico sinagogal. $\bigcirc$ "canto falado" ou cantilenas desenvolveu-se no sentido de uma melodia sintática que passou a ser utilizada nos serviços religiosos contribuindo para a institucionalização da cantilena. Os te' amim ha-mikra e os salmos, constituem uma parte muito significativa do repertório tanto instrumental como cantado nas sinagogas contemporâneas.

\section{A arte de cantar a Torá}

Torá em Hebraico significa "ensinamento". Um dos conceitos centrais do judaísmo, que pode se referir ao ensinamento judaico do Pentateuco e da bíblia hebraica, ou em um sentido mais amplo, a toda tradição judaica.

A prática da leita da Torá em público é muito antiga. $\bigcirc$ livro de Deuteronômio relata que depois de escrever sua épica "canção de despedida", Moisés reunião todo o seu povo e cantou-a "E escreveu Moisés este cântico naquele dia, e o ensinou aos filhos de Israel" (DEUTERONÔMIO, 3 1:22).

No Talmud de Jerusalém atribui a origem da leitura em público da Torá à Moisés e a Ezra. "Moisés decretou que a leitura da Torá deveria 
ser lida (cantada) no serviço da manhã, nos sábados e Festivais, na lua nova e nos dias intermediários dos festivais. . Ezra decretou que em Israel a Torá deveria ser lida (cantada) toda segunda e quinta-feira pela manhã e no serviço de sábado à tarde" (TALMUDE DE JERUSALÉM, MECILLAH 75a).

Cantar a Torá (bíblia hebraica), como toda arte requer detalhamento e aprimoramento constante. Envolve uma antiga tradição oral e costumes distintos de cada comunidade em que essas cantilações se desenvolveram. É chamado de te amim ha mikra ou cantilena que derivado do Latim cantare, que significa "cantar". Em uma sinagoga tradicional, este momento só poderá ser realizado por um Ba'al Keriah (mestre da leitura), uma pessoa muito bem preparada e qualificada, que cantara o texto sagrado para a congregação de acordo com as antigas tradições melódicas daquela comunidade, sem acompanhamento de qualquer instrumento, de forma livre quase cadencial e de carácter improvisatório.

\section{Procedimentos relativos a leitura da Torá}

canto litúrgico da Torá em público só pode ser realizado na presença um minyan (quórum de dez judeus adultos). A Torá é lida em cima de uma mesa especial chamada de Shulchan ou bimá. $\bigcirc$ rolo é colocado no meio da mesa e o ba'al keriah (leitor) em pé, sem se inclinar começa imediatamente a brachá (benção) que precede a leitura. Em honra da Torá o ba'al keriah usa um talit (manto usado nas rezas matinais). O oleh, pessoa que recebe a honra de fazer uma aliáh ${ }^{3}$ permanece à direita do leitor. Dos dois lados da mesa ficam em pé dois funcionários chamados gabaim.

primeiro gabai permanece em pé ao lado direito do leitor. Após cantar uma invocação, ele chamara cada oleh para a leitura da Torá. Depois de cada aliáh, o primeiro gabai pode cantar uma benção especial para o oleh. Bênçãos especiais podem ser adicionadas para aqueles que estiverem com doenças graves, ou receberam algum livramento ou aqueles que celebram uma grande alegria, assim como

3 Quando uma pessoa é chamada para recitar a benção que precede e a que sucede a leitura de um trecho do rolo da Torá diz-se que ela está realizando uma "subida à Torá ". Usa-se esta expressão porque a bimá, onde se lê a Torá, é geralmente uma plataforma elevada a que se chega subindo degraus. 
o nascimento de uma filho. $O$ segundo gabai, fica ao lado esquerdo do leitor assegurando-se que a Torá é coberta com sua vestimenta quando houver uma pausa grande entre as alyiot (plural de aliáh).

Ambos gabaim acompanham atentamente a leitura da Torá. Se o leitor cometer algum engano, o gabai interrompe a leitura e com muito cuidado, lembrando-lhe a pronúncia correta. $\bigcirc$ leitor então repetirá a frase com a correta pronúncia. Onde necessário, o gabai poderá atuar mais prontamente, cantando suavemente um pouco à frente do leitor ou através do uso das mãos, (quironomia), fazendo com que o leitor se lembre dos téamim a serem empregados naquele momento.

Quando o oleh é chamado, o leitor abrirá o rolo da Torá e apontará a palavra com a qual se inicia a leitura. $\bigcirc$ oleh toca a Torá com a ponta do talit, beija a parte do talit que tocou a Torá, canta a devida benção, enquanto segura a parte de madeira que sustenta o rolo de pergaminho.

oleh não olha em direção ao rolo enquanto diz a benção, ele deve dar a impressão que está lendo diretamente da Torá. Depois que - oleh terminou a benção, o ba'al keriah e a congregação respondem "amén". O ba'al keriah segura a alça esquerda com a sua mão esquerda enquanto que o oleh segura a alça direita, e começa a cantilação propriamente dita.

Deve-se ler cada palavra do rolo da Torá, nenhuma palavra deve ser lida de memóriat. Muitas comunidades têm o costume de apontar para cada palavra enquanto se lê com um apontador especial chamado yad (significa mão). Ele deve tomar cuidado para não tocar o apontador no rolo, pois, poderá trazer danos ao pergaminho.

O ba'al keriah deve cantar alto e claro o suficiente para que cada congregante possa ouvir e entender todas as palavras. Simultaneamente o oleh acompanha a leitura e se possivel, cantar suavemente ou ler junto do ba'al keriah. Ele deve cantar em pianissimo (suave), de forma a não ser ouvido pela congregação.

No final da aliáh, o oleh novamente toca a Torá com seu talit, beija a ponta do mesmo, fecha o rolo, e canta a benção final, enquanto

4 Ver Talmud Babilônico Gittin 60b: "Você não tem a liberdade de dizer de cor as palavras que estão escritas". 
segura às duas alças que sustentam o rolo. $\bigcirc$ ba'al keriah não deve interromper sua leitura, deixando o recinto, ou falar outras palavras que não sejam as do texto que esteja cantando. Entre uma aliáh e outra isto é permitido.

Após o último momento (sem contar o maftir), o oleh concluiu sua benção, o ba'al keriah recita um pequeno Kadish (oração para os enlutados). Depois que a leitura foi completada, o rolo é recoberto com sua vestimenta e adornos. Este ato é realizado com grande cerimônia, dois judeus são chamados para esta honra. $\bigcirc$ primeiro o magbiah, segura a Torá por suas alças e levanta-a com o pergaminho aberto para que todos da congregação vejam, em seguida senta-se com a Torá. $O$ segundo golel enrola o rolo e aperta-o, amarra uma faixa ao redor para que não venha a se desenrolar ou se separar, cobre com um manto e outros ornamentos.

Esses símbolos entoados pelo ba'al Keriah são sinais musicais chamados de te' amim ou ta' amei ha-mikra. A palavra "ta' am” em Hebraico significa "gosto" ou "razão", aludindo a um possivel maior esclarecimento o do texto. O termo é encontrado pela primeira vez no Talmud, טעמי ה תור " téamim da Torá (TALMUD Ber. 62.), refere diretamente às melodias do texto bíblico as quais serão entoadas.

\section{O texto massorético}

termo massora provem do hebraico de messorah e indica "tradição". Desta forma, os massoretas eram os guardiões da tradição, por assim dizer.

Não há referência clara sobre quando os téamim passaram a vigorar assim como as nekudot (pontos de vogais), em ambos, tanto no Talmud (compilado 500 d. C.) quanto na literatura midrashica deste período. A referência mais antiga que conhecemos dos téamim usados como símbolos gráficos musicais datam do nono século.

5 Refere-se adequadamente a última pessoa chamada à Torá nas manhãs do Shabat e feriados: esta pessoa também lê a porção da Haftará (separação ou porção) de uma seção relacionada aos Nevi'im (livros proféticos). 
Por volta do século VI, alguns escribas judeus reuniram vários textos considerados por eles de inspiração Divina, em um único compêndio. $\bigcirc$ resultado deste trabalho ficou conhecido posteriormente como "texto massorético".

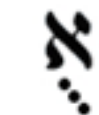

qubbutz kholam

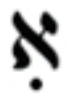

khIrik

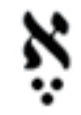

sEgol
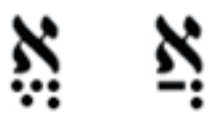

khataf sEgol

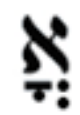

khataf qAmatz khataf kholam shUruk pAtakh maley

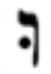
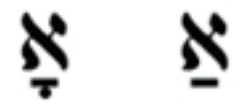

tzEre qAmatz

pAtakh
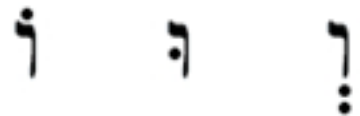

sh'va

Figura I - Vogais em Hebraico. Disponivel em: https://visionhelp.wordpress. com/20 12/07/07/arrowsmith-and-neuroplasticity-the-vision-connection/hebrew-vowels/

Por volta do final do IX d. C., os rabinos da escola de Ben Asher em Tiberíades desenvolveram um sistema de anotações de vogais, modificadoras de consoantes, e pontuações.

Estes símbolos são sobrepostos no texto consonantal resolvendo com isso muitos proble-mas de ambiguidades, esclarecendo pronuncias, inflexões e até mesmo elucidando a interpreta- ção. Esta escola introduziu dois novos grupos de símbolos.

Símbolos das vogais:

- Kamats, patah, holam, shuruk, kubuts, segol, tsere, sheva, hirik, hataf-patah, hataf-segol, e hataf-kamats.

Consoantes modificadas:

- Daguesh kal (distingue ente beit e veit, guimel e ghimel, dalet e dhalet, kaf e khaf, pey e fey, tav e thav). 
-. Daguesh hazak (o qual dobra o comprimento da consoante).

-. Mapik (o qual torna a letra hei no final de uma palavra de mudo para audivel e aspirada).

- $O$ ponto, que distingue entre shin e sin.

- O segundo grupo consiste no que podemos chamar de "acentos", os ta'amey ha-mikra; trinta símbolos se encontram na bíblia e vinte e três nos "livros poéticos". 


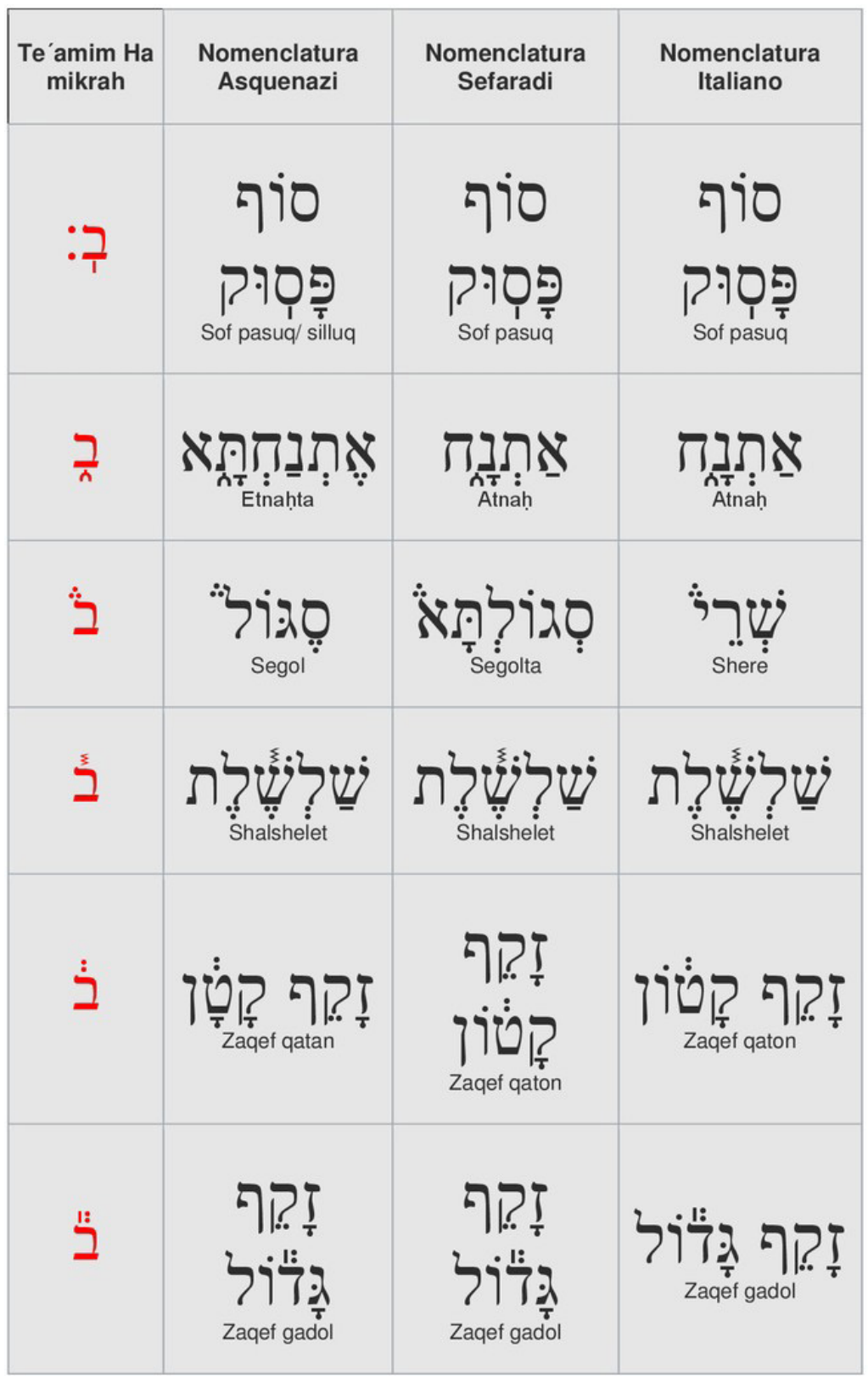

Figura 2 - Três diferentes nomenclaturas para cada te amim de acordo com a tradição italiana, ashkenazi e sefaradí. Fonte: https://en.wikipedia.org/wiki/Hebrew_cantillation 


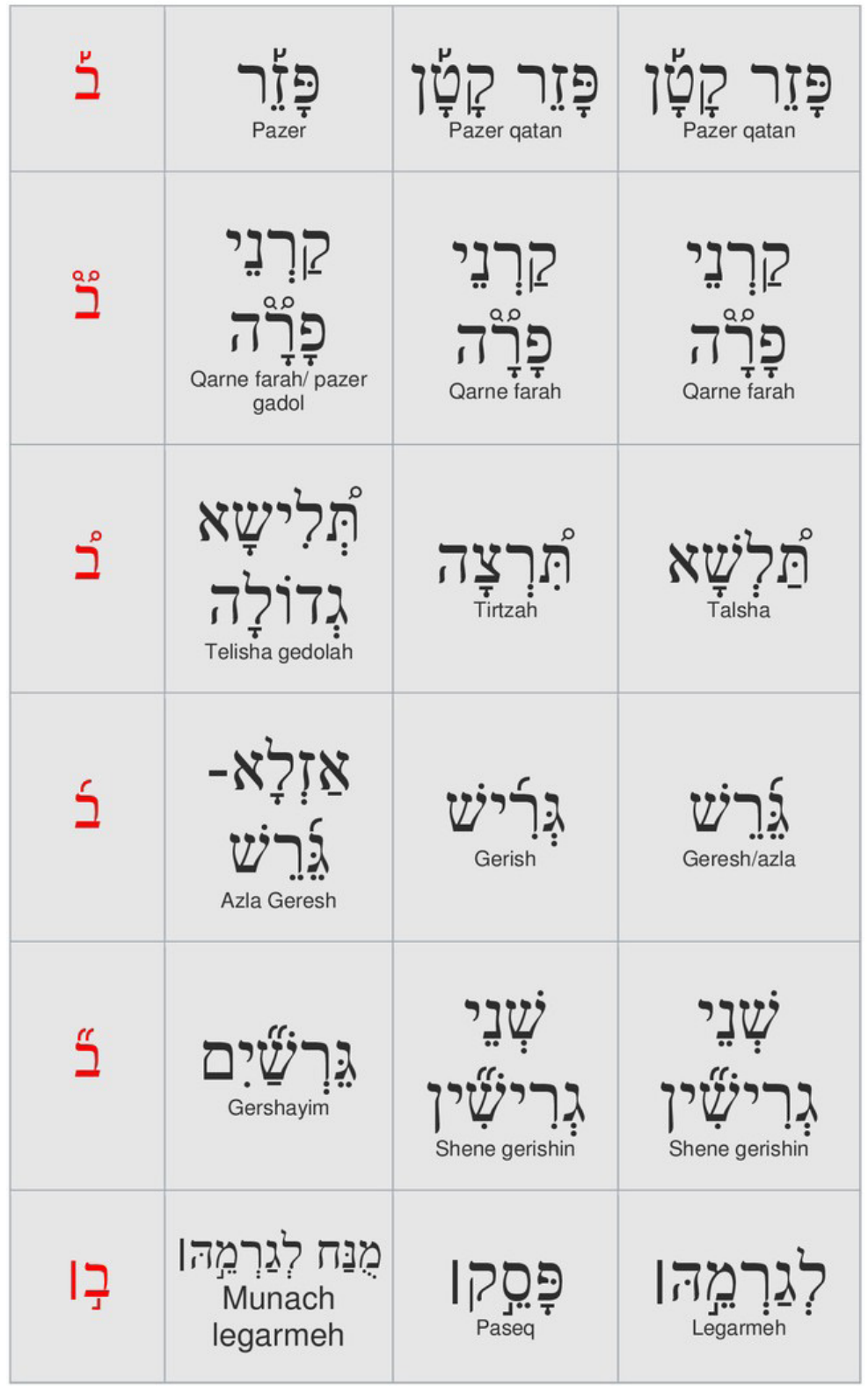

Figura 3 - Três diferentes nomenclaturas para cada te amim de acordo com a tradição italiana, ashkenazi e sefaradi. Fonte: https://en.wikipedia.org/wiki/Hebrew_cantillation 


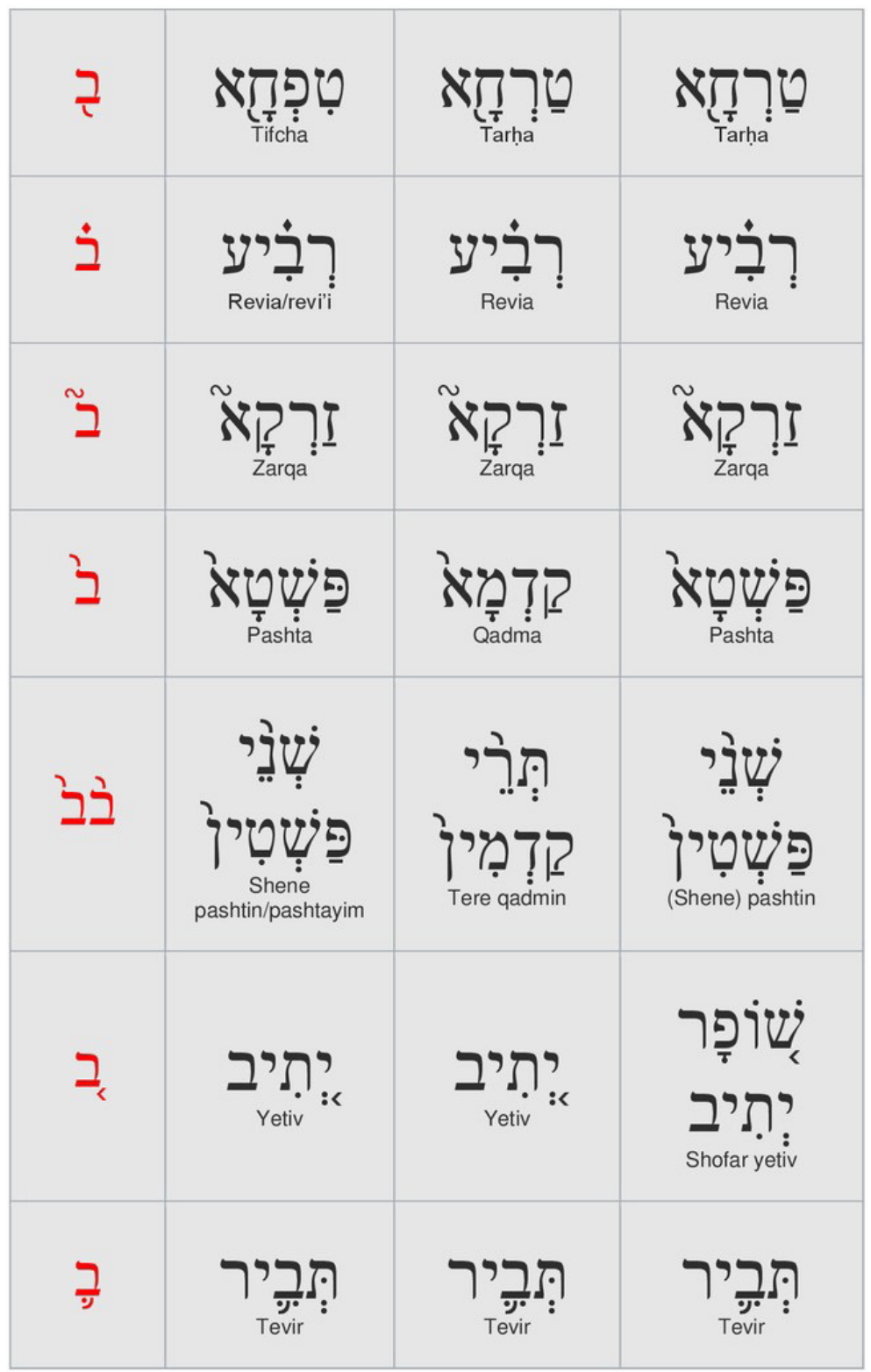

Figura 4 - Três diferentes nomenclaturas para cada te amim de acordo com a tradição Italiana, ashkenazi e sefaradí. Fonte: https://en.wikipedia.org/wiki/Hebrew_cantillation 


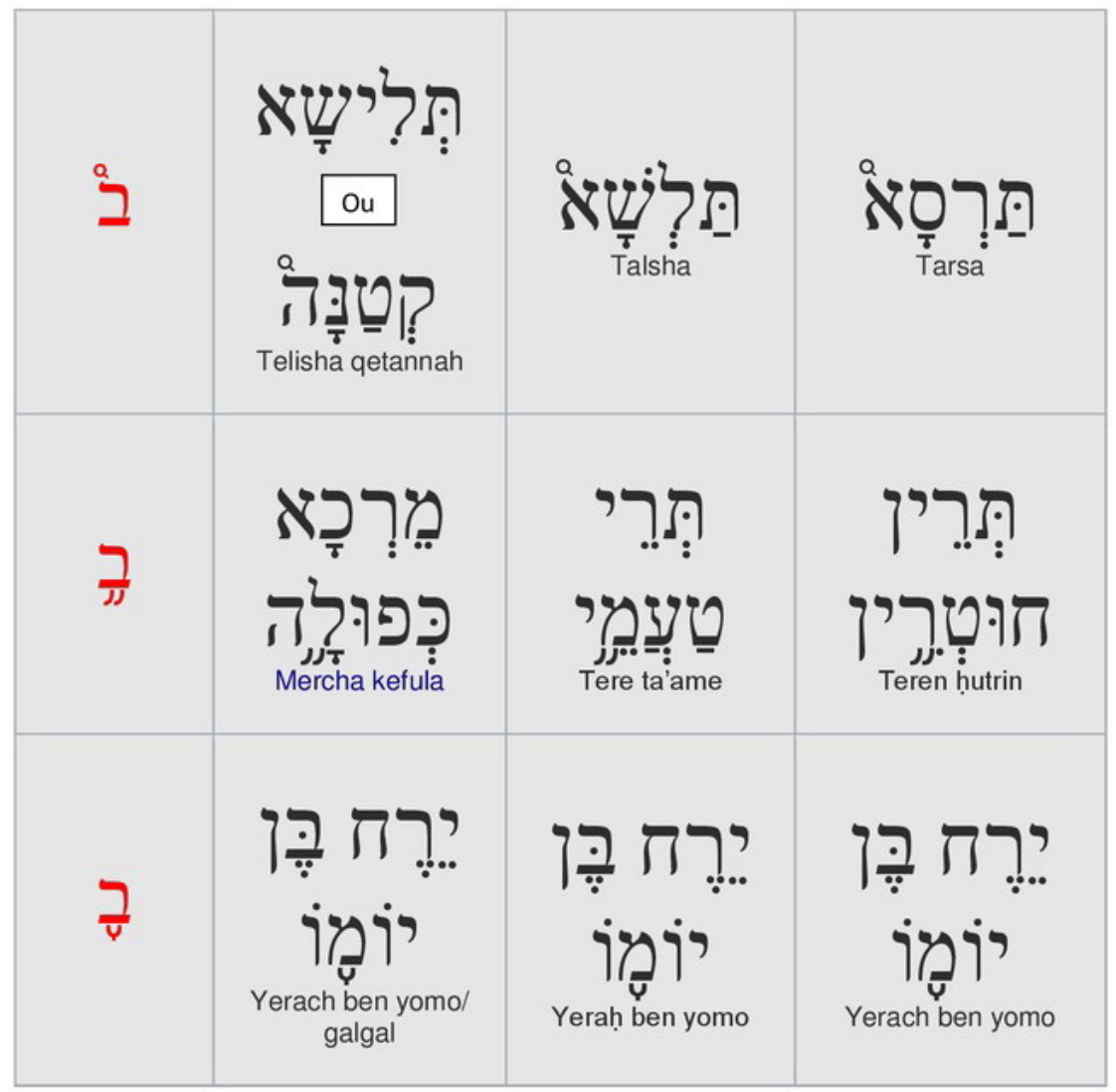

Figura 5 - Três diferentes nomenclaturas para cada te amim de acordo com a tradição italiana, ashquenazi e sefaradi. Fonte: https://en.wikipedia.org/wiki/Hebrew_cantillation

Os téamim oferecem três funções dentro do texto:

- Eles indicam a linha melódica sobre a qual as palavras serão cantadas.

- Eles indicam também qual silaba recebera a silaba tônica.

- Eles ajudam a elaborar um sistema de pontuação textual.

Essas três funções podem ser agrupadas em apenas um termo "inflexão". 
Este termo inflexão refere à subida e descida da tessitura vocal além de realçar determinadas palavras dentro da sentença trazendo assim um sentido e compreensão maior ao texto.

ritmo da cantilação é determinado pelas cadências naturais da fala. Flui de forma bem flexivel, mas com métrica. Esta métrica é definida previamente pelo símbolo a ser utilizado e está submetida à fluidez do texto assim como a melodia esta à serviço sintático do texto, valorizando pontos de maior interesse literário, sinalizando silabas tônicas e pontuações.

Utilizemos o símbolo tevir como exemplo. Em quase todas as tradições este símbolo tem uma primeira nota mais longa, segunda, terceira e quarta notas mais rápidas como se fossem um grupetto musical, que se resolve na mesma nota do inicio da passagem. Exemplo: sol como nota de inicio e mais longa (semínima), fá, mi, fá como notas do grupetto (colcheias), e sol como resolução do ornamento e também mais longa (semínima com fermata). Deve-se ter em mente que quando cantilamos um texto bíblico, as palavras devem ter uma atenção especial, pois, se trata do principal elemento, além de uma pronúncia clara e perfeita, inflexão significativa, e frase sintática logica.

Os téamim, os gráficos da cantilação, não representam em absoluto a tonalidade, assim como em símbolos musicais ocidentais tradicionais. Está muito mais voltado ao sistema modal, onde a música é pensada de forma horizontal, nota após nota, e não na relação de um agrupamento de notas tocadas simultaneamente, agrupamento este que o sistema tonal chamará de acorde (três ou mais notas tocadas simultaneamente). Para ilustrarmos a diversidade de interpretações dos te amim, tomaremos como modelo somente o símbolo "tevir".

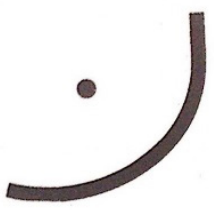

Figura 6 - Notação massorética de tevir. Fonte: https://en.wikipedia.org/wiki/ Hebrew_cantillation 
símbolo gráfico que representa tevir é uma curva com um ponto em seu centro. Tevir é uma palavra de origem Aramaica que significa "partido" ou "quebrado". Ceralmente é usado sob a primeira letra da sílaba tônica. Representa não um tom fixo apenas, mas um grupo de notas, que irá variar conforme for o texto a ser utilizado, a ocasião na qual será cantada no texto, e até mesmo o temperamento do intérprete poderá afetar o seu resultado. Qualquer tentativa de representar este símbolo para símbolos ocidentais será possivelmente mal compreendida justamente por todo caráter improvisatório que este símbolo poderá apresentar.

\section{Diversas interpretações para um mesmo símbolo}

Alguns musicólogos especulam que em tempo remoto em Israel poderia ter havido apenas uma forma de se cantar os téamim. Durante a diáspora, fora da terra de Israel, os judeus tentaram preservar as melodias da cantilação e guardá-las das mudanças que poderiam ocorrer. Entretanto, por onde passavam e se estabeleciam, acabavam influenciando e sendo influenciados pelos sons da cultura local. Se olharmos a figura sete, veremos que söo diferentes, mas que cada uma tem um contorno bem semelhante uma das outras. Na próxima figura temos as variações do tevir interpretado por sete diferentes comunidades judaica. 


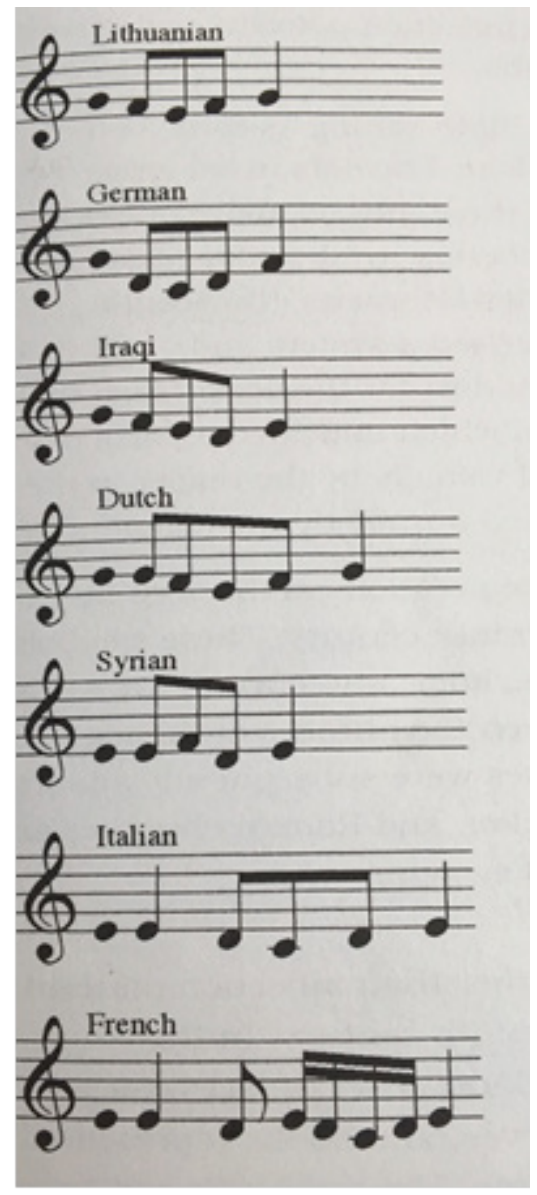

Figura 7 - Notação tevir interpretado em sete diferentes tradições. Fonte: JACOBSON Joshua, Chanting the Hebrew Bible.

Os téamim exercem a função de locução conjuntiva ou conjunto de palvras que atuam como conjução. Uma palavra conjuntiva é conectada com um disjuntivo que se segue. Apresenta ritmo mais rápido e geralmente sem pausa entre um conjuntivo (conector) e a próxima palavra. 


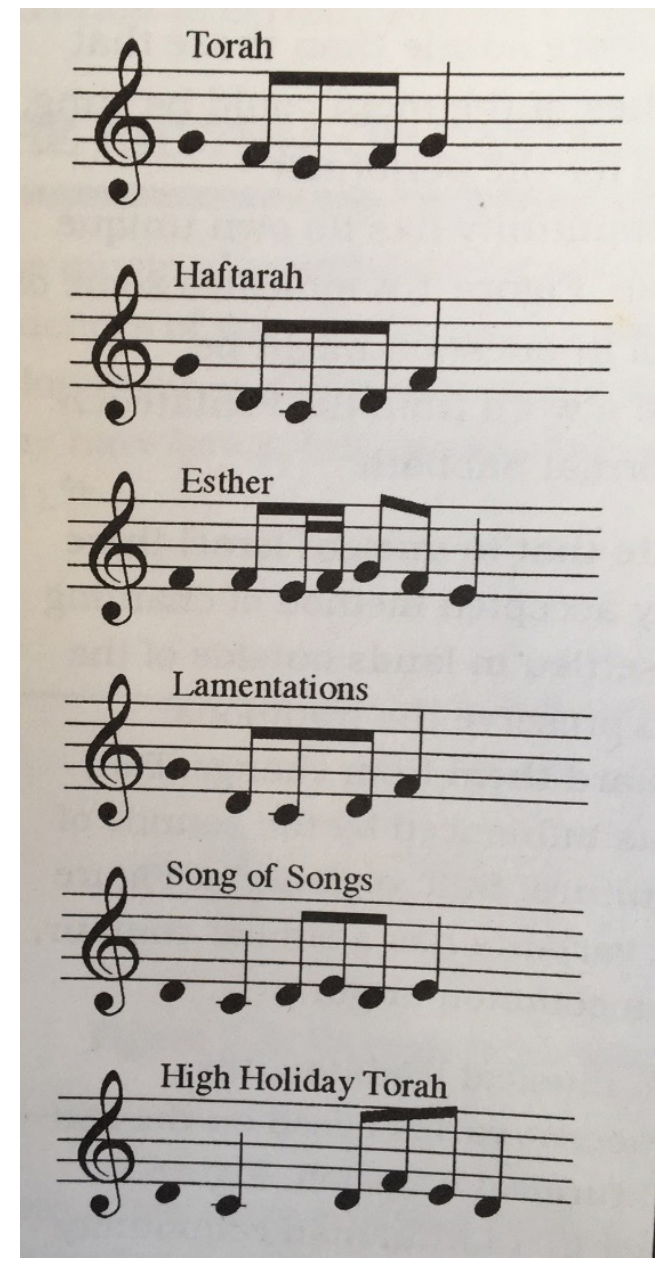

Figura 8 - Seis interpretações da notação tevir na tradição Lituana em momentos distintos da liturgia.

Fonte: JACOBSON Joshua, Chanting the Hebrew Bible.

Essas variações ocorrem praticamente em todos os outros te'amim aqui já mencionados. Não temos pretensão neste primeiro momento de pormenorizar cada um deles. 


\section{Notação ekfonética}

Os sinais gráficos utilizados para as melodias da cantilena são chamadas de notação ekfonética. ${ }^{6}$ Estas notações não pretendem indicar nenhum tom, diferentemente das notações ocidentais. Elas indicam padrões de inflexão e servem como um lembrete do motivo melódico.

Nos manuscritos siríacos da bíblia, no início do século quinto da Era Cristã, as inflexões são indicadas por vírgulas, ou sozinhas ou em um cluster de duas ou três, colocadas a cima ou a baixo da linha. Escritores Sírios criaram um sistema de vírgulas para os acentos, de forma que, cada qual indicava um significado particular, o que podia ser entendido pelo leitor da mesma forma que poderia ser reconhecido pelos ouvintes (SADIE; LATHAM; ZAHAR, 1994, volume 6, p. 99).

As notações ekfoneticas dos Cristãos Bizantinos podem ser vistos pelos manuscritos bíblicos do século nono. Estes símbolos, ou neumas, consistem de vírgulas, linhas e curvas; são escritas em vermelho, acima, abaixo e entre as frases do texto (SADIE; LATHAM; ZAHAR, 1994, volume 6, p. 101).

Alguns neumas Bizantinos, foram adaptados pelas igrejas Eslavas, Armênias e Romanas e posteriormente incorporadas em seus sistemas musicais.

A interpretação melódica dos téamim tem sido transmitida oralmente por centenas de anos. Em qualquer tradição oral, mudanças são constantes. Até que as melodias pudessem ser gravadas ou transcritas para um sistema de notação mais exato, as mudanças continuariam a ocorrer. A primeira transcrição dos téamim para uma notação ocidental foi feita no início do século XVI pelo estudioso da bíblia Cristã Caspar Amman (AVENARY, p. 11).

Caspar Amman foi um dos primeiros humanistas cristãos a entender a importância dos téamim para o entendimento da bíblia hebraica (AVENARY, 1978). Em seu livro de gramática hebraica, nunca publicado, continha uma transcrição para as anotações ocidentais das melodias dos téamim. A fonte de Amman para esta sua pesquisa foi Johannes

6 Ekfonética, palavra de origem Grega, significa "declinar", foi usado por I.Tzetzes em 1885 (New Grove Dictinary, volume 6, p. 99). 
Boeschenstein (1472-1540), foi ele que forneceu as mesmas informações para a mais conhecido das gramáticas hebraicas cristãs desse período, Johannes Reuchlin De accentibus et orthographia linguae Hebraicae (AVENARY, p. 11).

Muitos outros teólogos cristãos publicaram transcrições dos te'amim, mas todos esses trabalhos eram de cunho teórico e passaram praticamente despercebidos. Os judeus, entretanto, não liam textos em latim; sendo assim eles continuaram a transmitir suas melodias oralmente. Só depois de três séculos é que eles começaram a anotar os téamim (ADLER, 1989).

Somente quando um número significante de judeus se tornou familiarizado com as notações musicais ocidentais, houve um novo interesse por parte destes em transcrever as melodias tradicionais judaicas. Mesmo assim, eram judeus publicando para o uso apenas de judeus.

Muitos chazanim (cantores) ficaram bastante entusiasmados para experimentar as novas anotações ocidentais com seus alunos de canto. Os primeiros a publicar os te amim com as anotações ocidentais foram Isaac Nathan (Londres, 1823), Samuel Naumbourg (Paris, 1847), Salomon Sulzer (Viena, 1865), Abraham Baer (Cotemburgo, Suécia, 1877), e Israel M. Japhet (Frankfurt, 1896).

De acordo com Joshua Jacobson (JACOBSON, 2002) no século XX o estudo dos téamim passou a ter um foco acadêmico chegando às universidades. Solomon Rosowski (ROSOWSKY, 1957) escreveu uma análise sobre interpretação lituana dos acentos bíblicos. Abraham Zvi Idelsohn o pioneiro etnomusicólogo judaico, colecionou melodias dos te amim de diferentes lugares tais como da Europa, África do Norte, e Ásia Ocidental. Ele publicou suas transcrições em Thesaurus of Jewish Oriental Melodies (IDELSOHN, 1923) e fez uma análise comparativa em seu livro Jewish Music Its Historical Development. Johanna Spector, Robert Lachmann, e outros pesquisadores expandiram a coleção iniciada por Idelsohn. 


\section{Influências}

estudo das tradições musicais conservadas através de transmissão oral pelas comunidades judaicas parece, contudo, indicar que, a partir da baixa ldade Média, vieram progressivamente a se integrar na cultura musical dominante. Por exemplo, as comunidades sefarditas, oriundas da Península lbérica, têm como herança poéticomusical o romanceiro hispânico, com escalas e arabescos orientais. E a tradição musical ashkenazi reflete, quase sempre, um alto grau de dependência relativamente à cultura centro-europeia, havendo indicações de que essa dívida remonta já aos fins da época medieval (Idelsohn, p. 129-135).

Ė importante ressaltar a mutabilidade da tradição, tanto de cunho sinagogal de caráter sacro, como de repertório menos rígido pela liturgia. Em se tratando do repertorio sacro sinagogal, é possivel encontrar características comuns em comunidades cultural e geograficamente distantes derivadas de um mesmo arquétipo musical.

modo associado à cantilação do Pentateuco na tradição do sul e oriente do Mediterraneo e nas tradições italianas e portuguesas servem como exemplos, esta última documentada em Amesterdam, no século XVIII.

A cantilação usa um hexacorde de dó e lá e desenrola-se sobretudo em torno da nota mi, com ocasionais recitações sobre sol ou lá, vindo a terminar em mi, aproximado a partir de dó. Será este modo representativo da original música judia? Tradições hebraicas de antiguidade não menos venerável, como a do Yémen, desconhecem tal modo', pelo que se terá de supô-lo representativo não de uma hipotética tradição original, mas de uma tradição arcaica, entre outras. As transformações demográficas, sociais, e culturais ocorridas ao longo da ldade Média, e que tão profundamente afetaram a diáspora judaica ${ }^{8}$, tornaram arriscada a ideia de que a tradição modal do Pentateuco possa remontar à era terminal do Império Romano do Ocidente, período em que há notícia de importantes colônias hebraicas,

7 IDELSOHN, Avrahan Zevi, Jewish Music, p. 39-47.

8 BEN-SASSON, Hayim Hillel, A History of Jewish People, Cambridge, 1976. 
tanto na Península Itálica como na lbérica9. A hipótese de uma tradição oriental levada para terras hispânicas no seguimento da invasão árabe do século VIII, e adptada por judeus italianos sob influência oriental ou sefardita, é bastante mais plausivel (Ferreira, 1989).

Outros autores notaram semelhanças entre a música judaica e a música cristã. $\bigcirc$ musicólogo Israelense Hanoch Avenary fez uma análise e comparou as fontes impressas disponíveis dos cantos bíblicos da Tradição Ashkenazi entre 1500 e 1900. Eric Werner (UERNER, 1959) focou seus estudos na similaridade entre as tradições de cantilação judaica e Cristã.

Em suas pesquisas, ambos Werner e ldelsohn ficaram impressionados com a notável similaridade existente entre as tradições judaicas e cristãs; culturas que historicamente pouco interagiram. Eles chegaram a conclusão que muitos desses cantos existentes nas sinagogas e nas igrejas, originaram-se de uma fonte em comum: o Templo Central (Beit HaMikdash) na antiga cidade de Jerusalém. A mais antiga tradição musical de judeus e de cristãos traz consigo a reciprocidade.

Na complexa história humana, a dos judeus é apenas uma pequena linha tênue, que se prolonga muito além das fronteiras deste povo. Frequentemente, aparecem como uma espécie rara entre as nações. Um povo disperso em vários países até pouco tempo sem território próprio e nem língua comum. Não obstante, caracterizamse por um real sentimento de unidade e identidade comum. A cultura judaica é influenciada pelos países em que imigraram após se tornarem cativos. Uma cultura é influenciada e influência aqueles que dela fazem parte. Existe uma "troca" de conhecimento e costumes. Isto fica claro nos diversos "nuances" estilísticas aplicadas a um mesmo ta am entoado por diferentes comunidades judaicas.

Weber, afirma que uma comunidade se autodefine e estabelece as suas fronteiras, bem como estabelece meios de diferenciação tanto interna como externa. Os costumes vivenciados e criados por uma comunidade especificam e são capazes de gerar e garantir a sua sobrevivência e reprodução. "[...]Comunidade política, ou seja, está

9 Sobre os primeiros séculos de presença judaica na Península lbérica, consultar ICLESIAS, Luis Garcia, Los judios em la España antigua, 1978. 
voltada para ação, partilhando valores, costumes, uma memória comum, criando uma 'comunidade de sentido', independentemente de laços sanguíneos, na qual há um 'sentimento de pertencimento' [...]" (WEBER, 1995).

A música gera motivação na aprendizagem, prazer lúdico e estético em sua realização, elementos essenciais que podem consolidar o ideal utópico de cooperação entre os participantes e suas relações sociais.

A essência dos te amim ha- mikra consiste na busca contínua do desafio da qualidade e aperfeiçoamento da "mente coletiva judaica" e sua complexidade, oferece oportunidades de análises sócioorganizacionais para estudos posteriores.

\section{Referências}

ADENOT, P. Le musiciens d'orquestre symphonique. De la vocation au désenchantement. Paris: Editions L’Harmattan, 2008. 1989.

ADLER, I. Hebrew Notated Manuscript Sources. Munich: C. Henle,

AVENARY, H. The Ashkenazi Tradition of Biblical Chant between 1500 and 1900, 1978.

BEN-SASSON, H. H. A History of Jewish People, Cambridge, 1976.

BLOCH, M. Apologia da História. Zahar, 2002.

FERREIRA, M. P. Musica Judaica e Musica Cristã: Uma Herança Reciproca, 1989. https://www.academia.edu/1633741/M\%C3\%BAsica Judaica_e_M\%C3\%BAsica_Crist\%C 3\%A3_uma_heran\%C $3 \% A 7 a_{-}$ rec\%C3\%ADproca Acesso em 14 de abril de 2020. 1997.

FRIDLIN, J. Sidur Completo com tradução e trasnliteração. Sêfer,

COODMAN, A. Wörterbuch der Musik. Sudwest Verlag, 1982. 
GROUT, D. J. PALISCA, C. V. História da Música Ocidental. 4. Ed. Lisboa: Gradiva, 2007.

ICLESIAS, L. G. Los Judios em la España Antigua, 1978.

IDELSOHN, A. Z. Thesaurus of Oriental Hebrew Melodies: Sons of the Babylonian Jews. Berlim: Benjamim Harz, 1923. v. 2.

IDELSOHN, A. Z. Jewish music in its Historical Development. New York: Holt, Rinehart and Winston, 1929.

JACOBSON, J. R. Chanting the Hebrew Bible. Philadelphia: The Jewish Publication Society, 2002. 1983.

NETTL, B. The Study of Ethnomusicology. University of Chicago Press,

NOAJ, R. B. (Ed.). Talmud Babilônico. BN Publishing, 2012.

ROSOUSKY, S. The Cantilation of the Bible. New York: The Reconstructionist Press, 1957.

SADIE, S.; LATHAM, A.; ZAHAR, J. Dicionário Grove de Música. Rio de Janeiro:Jorge Zahar, 1994.

SMALL, C.; In UHITE, A. L. In Sociological Review Monograph 34. Lost in Music: Culture, Style and The Music Evente. London and New York: Routledge \& Kegan Paul, 1987.

TANACH KOREN. Jerusalém: Koren Publishers Jerusalem LTD., 2008.

UNTERMAN, A. Dicionário Judaico de Lendas e Tradições. 1. Ed. Rio de Janeiro: Zahar, 1992.

WEBER, M. Os Fundamentos Racionais e Sociológicos da Música. São Paulo: EDUSP, 1995.

UERNER, E. The Sacred Bridge: The Interdependence of Liturgy and Music in Synagoge and Church during the First Millennium. New York: Columbia University, 1959. 


\section{Sobre o autor}

Mestre pela Universidade de São Paulo em música, graduado pela Trinity College of London em Performance Violinística. Premiado nos principais concursos nacionais de música. Gravou ao lado de nomes importantes no cenário musical brasileiro. Ocupa-se com a pesquisa e com a grande arte do ensino sem deixar de ser um músico versátil e atuante em diferentes linguagens musicais.

Recebido em 30/07/2019

Aprovado em 06/05/2020 